NBER WORKING PAPER SERIES

\title{
THE IMPACT OF PHYSICAL EDUCATION ON OBESITY AMONG ELEMENTARY SCHOOL CHILDREN
}

\author{
John Cawley \\ David Frisvold \\ Chad Meyerhoefer \\ Working Paper 18341 \\ http://www.nber.org/papers/w18341
NATIONAL BUREAU OF ECONOMIC RESEARCH
1050 Massachusetts Avenue
Cambridge, MA 02138
August 2012

We gratefully acknowledge financial support from the Robert Wood Johnson Foundation, the Emory Global Health Institute, and a Faculty Research Grant from Lehigh University. We thank Griffin Edwards and John Zimmerman for research assistance. For helpful comments, we thank Charles Courtemanche, Inas Rashad Kelly, seminar participants, and conference participants at the American Economic Association annual meeting, American Society of Health Economics biennial meeting, NBER Health Economics program Spring meeting, and the Southern Economic Association annual meeting. We gratefully acknowledge financial support from the Robert Wood Johnson Foundation, the Emory Global Health Institute, and a Faculty Research Grant from Lehigh University. The views expressed herein are those of the authors and do not necessarily reflect the views of the National Bureau of Economic Research.

NBER working papers are circulated for discussion and comment purposes. They have not been peerreviewed or been subject to the review by the NBER Board of Directors that accompanies official NBER publications.

(C) 2012 by John Cawley, David Frisvold, and Chad Meyerhoefer. All rights reserved. Short sections of text, not to exceed two paragraphs, may be quoted without explicit permission provided that full credit, including $(\mathcal{C}$ notice, is given to the source. 
The Impact of Physical Education on Obesity among Elementary School Children

John Cawley, David Frisvold, and Chad Meyerhoefer

NBER Working Paper No. 18341

August 2012

JEL No. H75,I12,I18,I21,K32

\begin{abstract}
$\underline{\text { ABSTRACT }}$
In response to the dramatic rise in childhood obesity, the Centers for Disease Control (CDC) and other organizations have advocated increasing the time that elementary school children spend in physical education (PE) classes. However, little is known about the effect of PE on child weight. This paper measures that effect by instrumenting for child PE time with state policies, using data from the Early Childhood Longitudinal Study, Kindergarten Cohort (ECLS-K) for 1998-2004. Results from IV models indicate that PE lowers BMI z-score and reduces the probability of obesity among 5th graders (in particular, boys), while the instrument is insufficiently powerful to reliably estimate effects for younger children. This represents some of the first evidence of a causal effect of PE on youth obesity, and thus offers at least some support to the assumptions behind the CDC recommendations. We find no evidence that increased PE time crowds out time in academic courses or has spillovers to achievement test scores.
\end{abstract}

John Cawley

3M24 MVR Hall

Department of Policy Analysis and Management

and Department of Economics

Cornell University

Ithaca, NY 14853

and NBER

jhc38@cornell.edu

David Frisvold

Emory University

Department of Economics

1602 Fishburne Drive

Atlanta, GA 30322-2240

david.frisvold@emory.edu
Chad Meyerhoefer

Rauch Business Center

Lehigh University

621 Taylor Street

Bethlehem, PA 18015

and NBER

chm308@lehigh.edu 


\section{Introduction}

The prevalence of obesity among elementary schoolchildren in the United States nearly quadrupled between 1965 and 2000 (Ogden et al., 2002). ${ }^{2}$ As of 2009-2010, 32.6\% of American youths aged 6-11 years are overweight, and 18.0\% are obese (Ogden et al., 2012). The U.S. Surgeon General has declared childhood obesity to be an "epidemic” with significant adverse health consequences, including vascular disease and Type 2 diabetes (U.S. D.H.H.S., 2010), that significantly raise health care costs for youth (Trasande and Chatterjee, 2009; Trasande, Liu, Fryer et al., 2009).

The U.S. Surgeon General attributes the rise in childhood obesity, in part, to school cutbacks in physical education (PE) and urges all school systems to mandate daily PE that totals at least 150 minutes per week for elementary schoolchildren (U.S. D.H.H.S., 2010). Other organizations concur, including the American Academy of Pediatrics (AAP), Centers for Disease Control and Prevention (CDC), Institute of Medicine (IOM), and National Association of State Boards of Education (NASBE) (see, e.g., IOM, 2012; AAP, 2006). However, as of 2006, only $3.8 \%$ of elementary schools were in compliance with the recommendation of 150 minutes of PE per week (Lee et al., 2007).

Despite the recommendations of the Surgeon General, CDC, and others, there is little evidence of a causal effect of PE on youth obesity. There are several reasons that additional PE may not lower weight or the risk of obesity. First, PE classes may not involve much physical activity. Several studies have used direct observation or accelerometers to measure the amount of time that students spend physically active during PE; they conclude that elementary schoolchildren spend only 9-42\% of PE time engaged in moderate to vigorous physical activity

\footnotetext{
${ }^{2}$ For children, overweight is defined as a body mass index (BMI) above the historic 85th percentile of the BMI distribution for youth of the same age and gender, and obesity is defined as a BMI above the historic $95^{\text {th }}$ percentile (Barlow et al., 2007). BMI is calculated as weight in kilograms divided by height in meters squared.
} 
(Pate et al., 2011). A second issue is that students may offset any additional physical activity during PE by decreasing physical activity outside of school, with little net impact on physical activity or weight.

This paper contributes to the literature by estimating the causal effect of PE time on the weight of elementary schoolchildren. A large number of studies have reported the correlation of PE with student weight (see Pate et al., 2011, for a review). However, the correlation may be a badly biased estimate of the causal effect for several reasons. First, if enrollment is optional then there may be selection bias; physically fit students may be more likely to enroll. Second, the amount of required PE and enrollment in PE in a school may be correlated with the area's socioeconomic status (SES); e.g. higher-SES schools may require more PE, or may offer more or better PE courses, and may also have more physically fit students because of their higher SES. Alternatively, higher-SES schools may devote more time to academic subjects and less to PE.

A small number of studies estimate the causal effect of PE on youth weight. ${ }^{3}$ Cawley, Meyerhoefer, and Newhouse (2007) estimate the effect of PE time on the physical activity and weight of high school students, using variation in PE requirements across states as an instrument. Their IV models indicate that PE increases self-reported physical activity but has no detectable effect on the weight of high school students. Datar and Sturm (2004) study the effect of the increase in PE that results from progression from kindergarten to first grade, and find that an additional hour of PE time per week is associated with lower BMI in overweight or obese girls, but results in no change in BMI for healthy weight girls or for boys.

This paper examines the effect of PE on elementary schoolchildren (specifically, those in kindergarten through fifth grade). We analyze data from the Early Childhood Longitudinal

\footnotetext{
${ }^{3}$ There are also studies that involved randomized experiments of innovative PE curricula (for reviews, see Katz, 2009; Brown and Summerbell, 2008), but these studies are not informative about the effect of PE as it currently exists.
} 
Study, Kindergarten Cohort (ECLS-K). Our methods for identifying causal effects are described in the next section.

\section{Methods and Data}

The objective of this paper is to measure the causal effect of PE time on the weight of elementary schoolchildren. If PE time was randomly assigned, then one could regress child weight $W$ on time spent in PE (PE), controlling for a vector of relevant observables $X$ :

$$
W=\alpha+\beta P E+\delta^{\prime} X+\varepsilon
$$

and interpret the coefficient on PE time, $\beta$, as the causal impact of PE on weight.

However, PE time is not randomly assigned. Physically fit students may be more likely to choose PE, and the PE requirements and offerings of individual schools may be correlated with local SES. As a result, the error term $\varepsilon$ is likely correlated with the regressor of interest $P E$, and thus an OLS estimate of the coefficient of interest $\beta$ is likely biased.

In order to measure the causal impact of PE on weight, one needs to find a natural experiment that creates exogenous variation in PE time without directly affecting student weight (i.e. the instrument should be highly correlated with $P E$ but uncorrelated with $\varepsilon$ ). The natural experiment that we exploit is variation across states and over time in state requirements for PE for elementary schoolchildren. Using these state policies as instruments, we estimate models of instrumental variables in order to measure the causal effect of PE time on child weight. We cluster standard errors at the state level in all of our models because the instrument varies at the state level.

\section{Data: State PE Policies}


Our source for state policies regarding elementary school PE by year is the LexisNexis database of state statutes. These laws were cross-referenced with the Shape of the Nation Reports in 1993, 2001, and 2006, the Trust for America's Health (TFAH) annual reports that began in 2004, and the State School Health Policy database maintained by the National Association of State Boards of Education; we used these sources to determine when PE was first mandated if historical statues were unavailable in LexisNexis. ${ }^{4}$

There is significant variation across states in how the legislated mandates are written. For example, some states only require that PE be offered, but do not require that students enroll in it. States also differ in whether they recommend or require a minimum number of minutes per week that students spend in PE; some states specify both a recommended and required number of minutes. The instrument we use is the required number of minutes of PE per week. ${ }^{5}$ See Appendix Table 1 for details of the relevant laws by state.

\section{Data: Early Childhood Longitudinal Study, Kindergarten Class of 1998-99 (ECLS-K)}

The Early Childhood Longitudinal Study, Kindergarten Class of 1998-99 (ECLS-K) is a nationally representative survey of children entering kindergarten in the 1998-99 school year conducted by the National Center for Educational Statistics of the U.S. Department of Education (Institute of Education Sciences, 2009). ${ }^{6}$ The data were collected on children entering full day and part day kindergarten in either a public or private school. The ECLS-K collected information from children, their parents, their teachers and their schools, using a variety of

\footnotetext{
${ }^{4}$ The District of Columbia is excluded from this analysis because its statute wasn't available on LexisNexis and the Shape of the Nation and TFAH reports were inconsistent.

${ }^{5}$ The results reported below are robust to including as an additional instrument whether a state has a mandate at all (which may not involve a minimum number of minutes), whether the students are required to take PE (as opposed to schools only being required to offer PE), or the number of recommended minutes.

${ }^{6}$ The ECLS-K includes respondents from 41 of the 50 states. The states not included are: Arkansas, Idaho, Montana, Nevada, New Hampshire, North Dakota, South Carolina, Vermont, and West Virginia.
} 
methods. Trained assessors interviewed children in schools and measured their weight and height. Parents were surveyed by a trained interviewer over the phone, and teachers and school administrators completed paper and pencil surveys. For more information on the ECLS-K, see the User’s Manual (Tourangeau et al., 2009).

Data were collected during the fall and spring of kindergarten (1998-99), fall and spring of first grade (1999-2000), the spring of third grade (2002), the spring of fifth grade (2004), and the spring of eighth grade (2007), but not all of those waves are useful for this analysis. The fall kindergarten wave does not include information on the child's PE participation, so we use that wave only to extract certain time-invariant characteristics of children, such as their race and ethnicity. The wave from the fall of $1^{\text {st }}$ grade included only a $30 \%$ sub-sample of the original kindergarten cohort, so this wave is excluded from our analysis. We also exclude the $8^{\text {th }}$ grade wave because it did not record minutes of PE time.

We limit the sample to students attending public school because our identification strategy uses state requirements for PE as instruments, and these requirements apply only to public schools. We also limit the sample to students with non-missing values for state of residence and time spent in PE.

The body weight outcomes of interest ( $W$ in the model above) are: BMI z-score, an indicator for whether the child was obese (BMI $\geq 95$ th percentile of the age-gender specific BMI distribution), an indicator for whether the child was either overweight or obese (BMI $\geq 85$ th percentile of the age-gender specific BMI distribution), and the child's weight-for-age z-score. All z-scores and weight classifications are computed using the year 2000 release of the CDC Growth Charts (U.S. D.H.H.S, 2002); the z-scores measure the difference in standard deviation units between a given child's weight and the mean of the historic reference population. All of the 
weight variables are calculated using the measured weight and height recorded by the trained assessor during the school visit with the child.

The ECLS-K data also contain various measures of physical activity. In particular, parents are asked the number of days per week that their children exercise vigorously for 20 minutes or more, whether they are more or less active than other children of the same age, and whether they received regular exercise through various activities during the past 12 months. Information on relative physical activity was collected for structured activities at school, such as team sports, activities during the child's free time, and aerobic activities during which the child sweats and experiences increased heart rate. We created indicator variables for whether parents perceived their children to be more physically active than others for each of these three categories. We also created indicator variables for whether parents reported that their children received regular exercise during the past 12 months through the following activities: group sports, individual sports, recreational sports, general exercise, dance, karate, playground activities, and other sports.

The ECLS-K also asks parents how much time their children spend watching TV on school days as well as weekend days, which we use as a proxy for sedentary activities. We combined reported levels of TV watching on weekdays and weekend days to create a measure of total TV minutes per week.

Because of the age of the children, they were not considered to be reliable sources of information on their number of minutes of PE per week, so the ECLS-K collected the information from the best informed party: the student's teacher. Teachers reported the number of days per week that the student had PE class (the options are: never, less than once, 1-2 times, 3-4 time, or every day) and the minutes per day (the options are: $0,1-15,16-30,31-60$, or more 
than 60). We created one measure of days of PE instruction using the midpoint of the intervals and a second measure using the upper limit of the intervals. Likewise, we computed two measures of PE minutes per day; one using the midpoint of the intervals, using 75 minutes for the highest category, and one using the upper limit of the intervals, using 90 minutes for the highest category. We then generated three measures of how many minutes per week each child spent in PE by multiplying the following variables together: (1) midpoint for PE days/wk and the midpoint for PE minutes/day; (2) midpoint for PE days/wk and the maximum for PE minutes/day, and (3) maximum for PE days/wk and the maximum for PE minutes/day. All of the measures generated similar results in our empirical models, so we report the measure (2) because we think that daily instructional times are much more likely to correspond to the upper interval numbers, while the number of days per week of PE is likely to be uniformly distributed within the reported interval. Using the maximum values of PE minutes per day is conservative (i.e. we are potentially assuming children spent more time in PE than they actually did, so our impacts of PE times on outcomes should be attenuated).

In the waves for kindergarten through third grade, one teacher was asked to provide this information. However, in the fifth grade wave two teachers (reading and math) were asked to provide this information; in this case we use the average response across the two teachers. ${ }^{7}$

Because PE time is reported by teachers, and is furthermore reported in categories, there is likely measurement error in PE time that, without adjustment, biases estimates of the coefficient on PE time. An advantage of the method of IV is that, in addition to addressing the endogeneity of PE time, it reduces the bias from measurement error in the endogenous regressor; see Bound et al. (2002).

\footnotetext{
${ }^{7}$ Both teachers give similar estimates of time the child spends in PE; the mean (standard deviation) of reported weekly PE time is 100 (70) by the reading teacher and 101 (70) by the math/science teacher.
} 
The set of control variables ( $X$ in the model above) includes: child age, gender, race/ethnicity (White, Black, Hispanic, Other), birth weight, population density of residence (Urban Suburban, Rural), family income, family size, and the years of education of the most educated person in the family. Our models also include controls for grade, public school type (Charter school, Magnet school, Special education school, Bureau of Indian Affairs school, or Early childhood center), and the percentage of students at the school eligible for a free or reduced price lunch.

Policy endogeneity is a concern whenever policies are used as instruments (see, e.g., Cawley and Ruhm, 2012). That is, wealthier or more progressive states may pass higher standards in education, as well as have populations in better health for a variety of reasons. To address this possibility, we control for state characteristics related to income, education and health; specifically: real per capita income, the percentage of adults in the state with a bachelor's degree or higher, the state percentage of overweight and obese girls and boys, the state percentage of overweight adults, the average public school pupil-to-teacher ratio, real total state tax revenues per student, and real state instructional expenditures per teacher. Per capita income and adult education were obtained from the U.S. Census Bureau; the percentage of obese and overweight children was obtained from the Centers for Disease Control and Prevention; and the other variables were obtained from the U.S. Department of Education. Additionally, from the U.S. Department of Agriculture we obtained state participation per student in the National School Lunch Program (NSLP), School Breakfast Program (SBP), and Summer Food Services Program (SFSP). We use these measures to control for poverty, the quality of school meals, and access to food assistance. 


\section{Empirical Results}

\section{Summary Statistics and Descriptives}

Table 1 lists summary statistics for the ECLS-K variables used in the analysis. The average number of minutes per week spent in PE rises from 76 minutes in kindergarten to 87 minutes in $1^{\text {st }}$ grade, 91 minutes in $3^{\text {rd }}$ grade, and 104 minutes in $5^{\text {th }}$ grade. During elementary school, the prevalence of overweight rises from $26.1 \%$ in kindergarten to $40.5 \%$ in fifth grade, and over the same period the prevalence of obesity roughly doubles from $11.8 \%$ to $22.4 \%$.

Appendix Table 1 describes the PE requirements for elementary schools that prevailed in each state during each wave of the ECLS-K. Table 2 shows the change over time in state PE mandates. Between the ECLS kindergarten wave (1999) and the $5^{\text {th }}$ grade wave (2004), the number of states that did not mandate PE for elementary schoolchildren fell from 21 to 13 , and the number of states that required a specific number of minutes per week of PE for elementary schoolchildren rose from 2 to 11 . The increase in the number of states with PE mandates between the kindergarten wave in 1999 and the first grade wave in 2000 is due to the fact that many states require PE of $1^{\text {st }}$ graders but not kindergarteners (i.e. it is due to grade progression; no states changed PE requirements for first graders between 1999 and 2000). In contrast, the increase in the number of states with PE mandates between the first grade wave in 2000 and the fifth grade wave in 2004 is due to states enacting new PE mandates.

Figure 1 depicts the requirements as of 2004, the timing of the $5^{\text {th }}$ grade wave of the ECLS-K. In 2004, eleven states mandated a specific number of minutes of PE per week, and these states ranged from relatively liberal and high-SES states such as California, New York, and New Jersey, to relatively conservative and low-SES states such as Alabama, Mississippi, and 
Arkansas. In addition, 26 states mandated PE without specifying a minimum number of minutes, and 13 states did not mandate PE for elementary schoolchildren.

Table 3 lists the percent of ECLS-K students who were subject to a mandated number of minutes in PE. In kindergarten, only 6\% of the sample was subject to a PE mandate with a minimum required number of minutes. That jumped to $26 \%$ in $1^{\text {st }}$ grade, remained roughly constant at $27 \%$ in $3^{\text {rd }}$ grade, and jumped to $38 \%$ in $5^{\text {th }}$ grade.

\section{The impact of state policies on PE time $\left(1^{\text {st }}\right.$ stage of IV)}

The first stage of our IV method uses the state mandated number of PE minutes per week as an instrument for the number of minutes per week the child spends in PE. A reasonable question to ask is whether schools comply with these state mandates. For example, a study by the New York State government found that students in grades K through 3 received only $72 \%$ of the PE class time, and students in grades 4 and 5 received only $77 \%$ of the PE class time, that New York State required (Office of the New York State Comptroller, 2008). In general, the Institute of Medicine (IOM) has concluded that there is insufficient enforcement of state PE standards (IOM, 2006).

We calculated estimates of student compliance. Across all waves of the ECLS-K, only 34\% of students in states with a mandated number of minutes were in PE for the required number of minutes. Compliance varies with grade and year, from $17 \%$ in kindergarten to $31 \%$ in $1^{\text {st }}$ and $3^{\text {rd }}$ grades to $45 \%$ in $5^{\text {th }}$ grade. Less than perfect compliance by schools reduces the power of state mandates to affect individual student PE time.

The first stage of our IV model is reported in Table 4. The first stage is calculated for all waves pooled (column 1) as well as for each wave separately (subsequent columns). The results 
of the first column indicate that the instrument (number of required minutes) is a significant predictor of individual student PE time in the pooled sample. However, the subsequent columns reveal that this correlation is driven solely by the $5^{\text {th }}$ grade wave. Not only is the instrument only statistically significant in the $5^{\text {th }}$ grade wave, but the point estimate of the coefficient is several times larger in that wave than any other. Moreover, only in the $5^{\text {th }}$ grade wave does the $\mathrm{F}$ statistic associated with the instrument exceed 10, the conventional minimum standard for the power of a continuous instrument (Stock, Wright, and Yogo, 2002). Specifically, the F statistic in the $5^{\text {th }}$ grade wave is 21.7 .

The point estimate of the coefficient on the instrument indicates that a state mandate of an additional 100 minutes of PE per week translates into an actual increase in PE time of only 13 minutes for kindergarteners, 2 minutes for first-graders, 4 minutes for third-graders, and 40 minutes for $5^{\text {th }}$ graders.

The statistical significance of the instrument in the $5^{\text {th }}$ grade wave, as opposed to any other, is driven by increases in state-mandated PE time between 2002 (the $3^{\text {rd }}$ grade wave) and 2004 (the $5^{\text {th }}$ grade wave). The average number of minutes per week spent in PE in states with a minute requirement was 89 in 2002, but that rose to 127 in 2004. This increase is the result of both new states adopting minutes requirements (that were substantial) between 2002 and 2004, and increases in PE time among states that had enacted minutes requirements earlier (in particular, those that adopted them prior to 2000).

\section{The effect of PE time on child weight $\left(2^{\text {nd }}\right.$ stage of IV)}

Table 5 presents results of the second stage of IV, and (for the sake of comparison), results from OLS regressions. We continue to present results for the pooled sample, as well as 
for each wave individually, and we focus in particular on the results for the $5^{\text {th }}$ grade wave, given that the instrument is sufficiently powerful only in that wave.

In the $5^{\text {th }}$ grade wave, the IV coefficient on PE minutes is negative and statistically significant at the $1 \%$ level. The point estimate implies that an additional 50 minutes per week in $\mathrm{PE}$ (roughly what is needed to bring the mean up to the minimum amount recommended by the AAP and CDC) would lower BMI z-score by 8 percent of a standard deviation, or 12 percent of the mean BMI z-score in the sample. The negative sign of the IV coefficient in the $5^{\text {th }}$ grade wave (final column) is consistent with the sign of the corresponding OLS coefficient (second-tolast column), although the IV point estimate is greater in absolute magnitude than that from OLS; this difference may be due to IV correcting for measurement error in PE time, or may be a result of the OLS estimate being biased by selection or omitted variables.

We report the results of IV models for other weight outcomes in Table 6. These estimates are based on the $5^{\text {th }}$ grade wave only, because it is only in that wave that the instrument is sufficiently powerful. The IV models indicate that PE reduces the probability of overweight, obesity, and the weight z-score; in each case the IV coefficient is statistically significant at the 1\% level. The point estimate implies that an additional 50 minutes per week in PE (roughly enough to raise the mean to the amount recommended by the AAP and CDC) reduces the probability of youth obesity by 4 percentage points, which is 18 percent of the baseline prevalence.

In summary, for each of the four measures of weight (BMI z-score, weight z-score, overweight, obese), the IV model consistently finds that PE time reduces child weight.

We also investigate mechanisms, and the possibility of offsetting behavior, in Table 7. There, we report the results of IV models of PE time on various measures of overall physical 
activity, as reported by the parent. The IV results, presented in Table 2, suggest that additional PE leads to greater overall participation in structured physical activity and more physical activity overall. There may also be some crowd-out, however, as the IV models also indicate that additional PE time reduces the probability of participation in dance and in playground activities. For the remaining activities (including days per week of vigorous exercise, participation in other specific physical activities and TV minutes per week) we cannot reject the null hypothesis of no effect of PE.

\section{Falsification Tests:}

When using policies as instruments, one must be wary of policy endogeneity (e.g. Cawley and Ruhm, 2012). Because we are concerned that states which enact or raise PE minute mandates may differ in important ways from those which do not, we control in our models for a wide variety of state characteristics relating to income, health, and education. Consistent with a lack of policy endogeneity, no state characteristics are statistically significant at the 5 percent level (and only one of 12 is significant at the 10 percent level) in regressions of the required number of PE minutes on the set of state characteristics in 2004, which is the year of $5^{\text {th }}$ grade wave of the ECLS-K. Likewise, no state characteristics in 2002 are significantly associated with the change in required number of PE minutes between 2002 and 2004. However, it is possible that even controlling for these observed characteristics, there may remain a problem of policy endogeneity that would imply our instrument is invalid and the IV estimates are biased.

To investigate this possibility we conduct several falsification tests. Specifically, we estimate our IV model for the following weight-related outcomes: birth weight, BMI in the fall semester of kindergarten, and height z-score. These are not plausibly affected by PE in 
elementary school, so a correlation with PE time would imply that our instrument is invalid.

Results of the falsification test are shown in Table 8. In no case does the IV model suggest that PE time affects any of these three outcomes; none of the IV coefficients comes close to being statistically significant. ${ }^{8}$ These results should be interpreted cautiously; a failure to reject the null hypothesis does not prove the null. However, the falsification tests yield no evidence of policy endogeneity and are consistent with our identifying assumptions.

\section{Extension: Crowd-Out of Academic Class Time, Spillovers to Academic Achievement}

As an extension, we test whether there are unintended consequences of mandating additional PE time, specifically whether a higher number of mandated minutes crowds out time in academic classes, or has spillover effects on academic test scores.

To test for crowd-out, we estimate the same IV model as earlier, except that the dependent variable is the number of minutes in specific academic classes, such as reading, writing, math, social studies, science, and foreign languages. We also examine time spent in enrichment classes, such as music and art, as well as in lunch and recess. ${ }^{9}$

The results of these models are presented in Table 9. The IV results, in the center column, indicate that increased PE time does not lead to a significant crowd-out of time in any academic class. The only significant decrease in class time is for music; a one-minute increase in PE time is associated with a 0.2 minute decrease in music class. Instead of schools cutting academic classes when PE mandates are increased, they seem to increase the length of the school

\footnotetext{
${ }^{8}$ Consistent with the estimates in Table 8, the main results are robust to controlling for fall kindergarten BMI zscore.

${ }^{9}$ As described in the appendix, of the 11 states with a minimum required number of minutes for $5^{\text {th }}$ grade in 2004 , only Texas requires physical activity more generally, which may include recess in addition to PE. The results in Table 9 show that state PE requirements and time in PE are not associated with a change in time spent in recess. Additionally, the main results are robust to excluding students in Texas from the sample. Thus, the results throughout the paper reflect the impact of PE, as opposed to physical activity more generally.
} 
day. The first row of Table 9 shows that a one-minute increase in mandated PE time is associated with a 1.6 minute increase in the length of the school day.

Based on these findings, one would not expect raising PE mandates to lower scores on achievement tests. On the contrary, some have argued that PE may improve achievement test scores, as physical activity may enhance cognitive functioning (e.g. Tomporowski, 2003). However, the results of IV models of the impact of PE on achievement test scores (presented in Table 10) consistently yield no evidence of spillover effects of PE on achievement test scores for reading, math, or science.

\section{Subgroup Analyses: Differences by Gender}

We also investigate whether the relationship between additional PE time and weight varies by gender. IV models were estimated separately by gender, and results are presented in Table 11. The F statistics for both boys and girls exceed the conventional minimum threshold of 10 (18.2 for girls, 25.8 for boys), and the first-stage coefficients are similar for both boys and girls (0.401 for girls, 0.395 for boys).

The IV results in Table 11 indicate that increased PE time reduces weight only for boys; the reduction is statistically significant for all three measures of weight (BMI z-score, overweight, and obese). In the IV models, an additional 50 minutes of PE time reduces BMI zscore by .15 of a standard deviation, and reduces the probability of overweight and the probability of obesity by 6 percentage points. Although the probit models indicate that girls who spend more time in PE are less likely to be overweight and obese, the IV coefficients are not statistically significant, and thus it is not possible to reject the null hypothesis that additional PE time has no effect on weight for elementary school girls. 


\section{Discussion}

This paper estimates IV models of the effect of PE time on child obesity. The IV models address both endogeneity of PE time and measurement error in PE time. The results of the IV models indicate that an additional 50 minutes per week of PE time (enough to raise the mean to the amount recommended by the AAP and CDC) lowers BMI z-score by 12 percent of the mean, and reduces the probability of obesity by 4 percentage points.

Our results are limited to $5^{\text {th }}$ graders (i.e. the 2004 wave of ECLS-K), because it was around that time that a substantial amount of variation in the relevant policies occurred. First, as noted above, there was an increase in the number of states adopting PE requirements with a minimum number of minutes. Second, the $5^{\text {th }}$ grade wave of the ECLS-K, which is the 20032004 school year, was the first wave under which the formal school accountability policies enacted under No Child Left Behind (NCLB) would have been effective. In response to accountability pressures, schools may decrease the amount of time in PE to offer more time in the tested subjects (Pate et al., 2006). Consistent with this possibility, Anderson, Butcher, and Schanzenbach (2012) and Yin (2012) find that accountability policies increase childhood obesity. Thus, state PE requirements would be more effective in increasing time spent in PE in the 2004 wave of the ECLS-K because these requirements limited schools’ ability to strategically respond to the accountability pressures of NCLB.

Our subgroup analyses indicate that the effects of PE on weight in the $5^{\text {th }}$ grade wave are concentrated among boys. This may be due to factors on the supply side (boys may voluntarily be more physically active during PE) or factors on the demand side (PE teachers may structure different activities for boys and girls in PE, or demand more of boys in the same activities). 
Better understanding gender differences in the impact (and curriculum) of PE is clearly a priority for future research.

Although we find beneficial effects of PE on weight for only certain grades (waves), and only for boys, these results offer some of the first confirmation of an important assumption behind the calls by the CDC, AAP, IOM, and other groups for school districts to increase required PE time for elementary schoolchildren in order to prevent obesity.

More generally, this study represents a response to the call of the IOM to evaluate the effects of policies and programs and thereby increase the knowledge base regarding what works to prevent childhood obesity (IOM, 2006). This information is valuable because childhood obesity is associated with impaired health, social stigma, and elevated health care costs (IOM, 2005).

What policymakers would most like to know is the Average Treatment Effect (ATE) of PE, but what is estimated by IV models is the Local Average Treatment Effect (LATE). The LATE may differ from the ATE if state mandates increase PE only in certain types of schools. For example, high-SES schools may already satisfy the new mandate (because they have more of everything) or may be less likely to already satisfy the new mandate (if they are focused on academics to the exclusion of PE). In addition, the instrument was sufficiently powerful only in 2004 (the $5^{\text {th }}$ grade wave of ECLS-K) and if the treatment effect is heterogeneous with age then the results for $5^{\text {th }}$ graders may not generalize to schoolchildren of other ages. In related work, Cawley, Meyerhoefer, and Newhouse (2007) used PE unit credit requirements (i.e. mandates in the form of semester courses rather than minutes per week) as instruments for PE time during high school, and found no detectable impact of additional PE on high school students' BMI or 
the probability of obesity. ${ }^{10}$ As with gender, it is clearly a priority for future research to better understand how the curriculum of PE, and the effect of PE, vary by grade and age.

Our findings confirm earlier studies that found weak compliance by schools with state PE mandates (e.g. IOM, 2012; IOM, 2006). Our estimates indicate that an increase of 100 minutes in the state mandate translates into only 40 additional minutes of PE class time among $5^{\text {th }}$ graders. To some extent, the less than one-to-one correspondence may be driven by some schools already satisfying the mandate, but we consistently find that only a minority of students are compliant with state mandates. This suggests that states wishing to increase youth physical activity may wish to enforce existing PE mandates, in addition to raising the number of mandated minutes (IOM, 2012).

The results of this paper indicate that increased PE leads to greater overall participation by elementary schoolchildren in structured physical activity and more physical activity overall. Beyond its impact on youth weight, this is important because increased physical activity by youths is associated with cardiovascular benefits such as a reduction in low-density lipoproteins (bad cholesterol) and the prevention or delay of hypertension; musculoskeletal benefits such as increased bone-mineral density and increased strength and endurance; mental and emotional benefits such as reduced stress and anxiety; and prevention of chronic disease (IOM, 2005).

This paper finds no evidence that additional PE time crowds out academic subjects. We also find no evidence that PE has any spillover effects onto achievement test scores. These findings are consistent with those of Dills et al. (2011).

\footnotetext{
${ }^{10}$ Cawley, Meyerhoefer, and Newhouse (2007) used PE credit units, rather than minutes per week, as an instrument, because the former are the way in which state requirements for high school students are expressed: in terms of semesters of coursework needed to graduate. This paper uses minutes per week as an instrument because state requirements for elementary school students are expressed in terms of minutes per week rather than credit units for graduation. That is, in each paper the instrument matches the way state laws express requirements for the grades involved.
} 
Concerned by the possibility of policy endogeneity that might bias the IV estimates, we control in our models for a host of state characteristics related to income, education, and health, including per capita income, education levels, prevalence of obesity, pupil-to-teacher ratio, tax revenues per student, expenditures per teacher, and participation in subsidized school meal programs. Moreover, we conduct several falsification tests and find no evidence that increased PE time affects weight-related variables that it shouldn’t, specifically: birth weight, BMI z-score in the fall of kindergarten, and height z-score. In summary, we find no evidence that policy endogeneity biases the IV results, but caution that evidence from falsification tests is only suggestive, not definitive.

A limitation of this paper is that the weight-related outcomes we examine (BMI z-score, overweight, obesity) are based on body mass index, which is a flawed measure of fatness because it ignores the distinction between fat and muscle (Burkhauser and Cawley, 2008). Physical activity that builds muscle and burns fat will have an ambiguous impact on BMI. An ideal dataset would include measures of both fat mass and lean mass (which can be calculated using technology such as Bioelectrical Impedance Analysis or Dual X-Ray Absorptiometry), allowing researchers to measure the effect of PE on muscle and fat. However, this limitation is less relevant for elementary school students, whose PE involves less muscle-building exercise and who are less prone than adolescents to adding muscle mass. 


\section{Works Cited}

American Academy of Pediatrics. 2006. Active Healthy Living: Prevention of Childhood Obesity Through Increased Physical Activity. Pediatrics 117(5): 1834-1842.

Anderson, Patricia M., Kristin F. Butcher, and Diane Whitmore Schanzenbach. 2012. “Adequate (or Adipose?) Yearly Progress: Assessing the Effect of 'No Child Left Behind' on Children's Obesity” working paper.

Barlow, S.E., the Expert Committee., 2007. Expert Committee recommendations regarding the prevention, assessment, and treatment of child and adolescent overweight and obesity: summary report. Pediatrics 120(Suppl 4), S164-92.

Bound, J., Brown, C., Mathiowetz, N., 2002. "Measurement error in survey data.” In: Heckman, J., Leamer, Ed. (Eds.), Handbook of Econometrics, vol. 5. Springer- Verlag, New York, pp. 3705-3843.

Brown T, Summerbell C. 2009. "Systematic review of school-based interventions that focus on changing dietary intake and physical activity levels to prevent childhood obesity: an update to the obesity guidance produced by the National Institute for Health and Clinical Excellence.” Obesity Reviews, 10: 110-141.

Burkhauser, R.V., Cawley, J. 2008. "Beyond BMI: the value of more accurate measures of fatness and obesity in social science research.” Journal of Health Economics, 27(2), 519529.

Cawley, John, Chad Meyerhoefer, and David Newhouse. 2007. “The Impact of State Physical Education Requirements on Youth Physical Activity and Overweight.” Health Economics, 16(12): 1287-1301.

Cawley, John, and Christopher J. Ruhm. 2012. “The Economics of Risky Health Behaviors.” Chapter 3 in: Thomas G. McGuire, Mark V. Pauly, and Pedro Pita Barros (editors), Handbook of Health Economics, Volume 2. (Elsevier: New York), pp. 95-199.

Datar A, Sturm R. 2004. Physical education in elementary school and body mass index: evidence from the early childhood longitudinal study. American Journal of Public Health 94(9): 1501-1506.

Dills, A.K., H.N. Morgan, and K.W. Rotthoff. 2011. "Recess, physical education, and elementary school student outcomes.” Economics of Education Review 30: 889-900.

Institute of Education Sciences. 2009. Combined User's Manual for the ECLS-K Eighth-Grade and K-8 Full Sample Data Files and Electronic Codebooks. National Center for Education Statistics, U.S. Department of Education: Washington, D.C.

Institute of Medicine. 2005. Preventing Childhood Obesity: Health in the Balance. National Academies Press: Washington, DC.

Institute of Medicine. 2006. Progress in Preventing Childhood Obesity: How do we Measure Up? National Academies Press: Washington, DC.

Institute of Medicine. 2012. Accelerating Progress in Obesity Prevention: Solving the Weight of the Nation. Washington, DC: The National Academies Press.

Katz, DL. 2009. "School-Based Interventions for Health Promotion and Weight Control: Not Just Waiting on the World to Change.” Annual Review of Public Health , 30:253-72. 
Lee SM, Burgeson CR, Fulton JE, Spain CG. 2007. "Physical education and physical activity: results from the School Health Policies and Programs Study 2006.” Journal of School Health, 77(8): 435-463.

Office of the New York State Comptroller. 2008. School Districts’ Compliance With Physical Education Regulations. 2008-MS-6. http://www.osc.state.ny.us/localgov/audits/swr/2008/physical_ed/physical_edfinal.pdf

Ogden, C. L., Carroll, M. D., Kit, B.K., Flegal, K. M. 2012. "Prevalence of Obesity and Trends in Body Mass Index Among US Children and Adolescents, 1999-2010.” Journal of the American Medical Association 307(5), E1-E8.

Ogden, C. L., Flegal, K. M., Carroll, M. D., Johnson, C.L. 2002. "Prevalence and Trends in Overweight Among US Children and Adolescents, 1999-2000.” Journal of the American Medical Association 288(14), 1728-1732.

Pate, Russell R., Michael G. Davis, Thomas N. Robinson, Elaine J. Stone, Thomas L. McKenzie, and Judith C. Young. 2006. "Promoting Physical Activity in Children and Youth: A Leadership Role for Schools: A Scientific Statement from the American Heart Association Council on Nutrition, Physical Activity, and Metabolism (Physical Activity Committee) in Collaboration with the Councils on Cardiovascular Disease in the Young and Cardiovascular Nursing," Circulation, 114(11): 1214-1224.

Pate, Russell R., Jennifer R. O’Neill, and Kerry L. McIver. 2011. "Physical Activity and Health: Does Physical Education Matter?” Quest, 63: 19-35.

Stock JH, Wright JH, Yogo M. 2002. "A survey of weak instruments and weak identification in generalized method of moments.” Journal of Business and Economic Statistics 20(4): 518-529.

Tomporowski PD. 2003. “Cognitive and behavioral responses to acute exercise in youths: a review.” Pediatr Exerc Sci. 15: 348-359.

Tourangeau, K., Nord, C., Lê, T., Sorongon, A. G., and Najarian, M. 2009. Early Childhood Longitudinal Study, Kindergarten Class of 1998-99 (ECLS-K), Combined User's Manual for the ECLS-K Eighth-Grade and K-8 Full Sample Data Files and Electronic Codebooks (NCES 2009-004). National Center for Education Statistics, Institute of Education Sciences, U.S. Department of Education. Washington, DC.

Trasande L, Chatterjee S. 2009. "The impact of obesity on health service utilization and costs in childhood.” Obesity, 17:1749-54.

Trasande L, Liu Y, Fryer G,Weitzman M. 2009. "Effects of childhood obesity on hospital care and costs, 1999-2005.” Health Affairs, 28(4): w751-60.

US Department of Health and Human Services. 2002. 2000 CDC growth charts for the United States: methods and development. Vital and National Health Statistics, Series 11, Number 246, May.

U.S. Department of Health and Human Services. 2010. The Surgeon General's Vision for a Healthy and Fit Nation. Rockville, MD: U.S. Department of Health and Human Services, Office of the Surgeon General, January.

Yin, Lu. 2012. “Are School Accountability Systems Contributing to Adolescent Obesity?” working paper. 
Figure 1

State PE Requirements for Elementary School Students in 2004

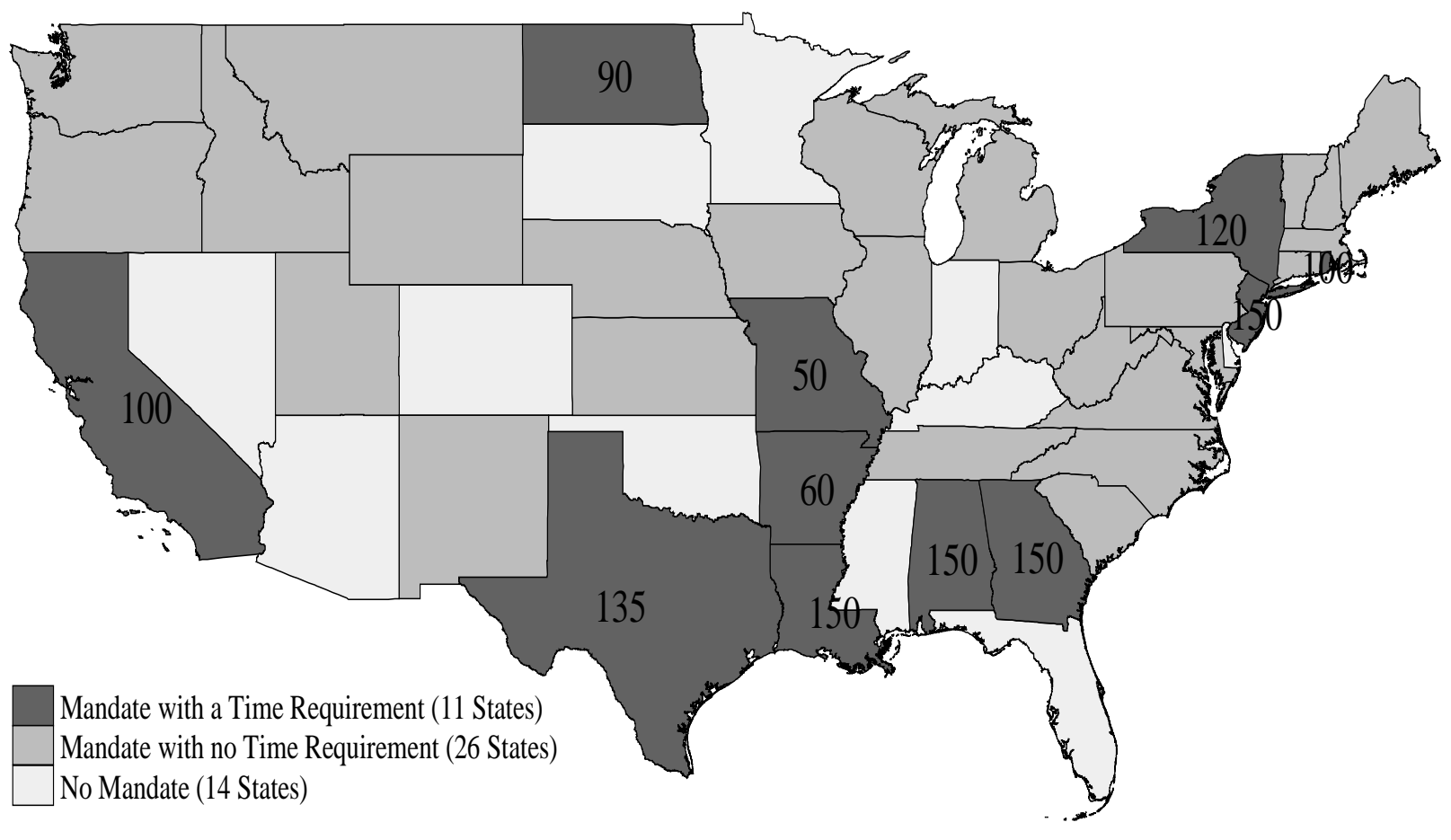

Note: 2004 corresponds to the $5^{\text {th }}$ grade wave of ECLS-K 
Table 1:

Descriptive Statistics

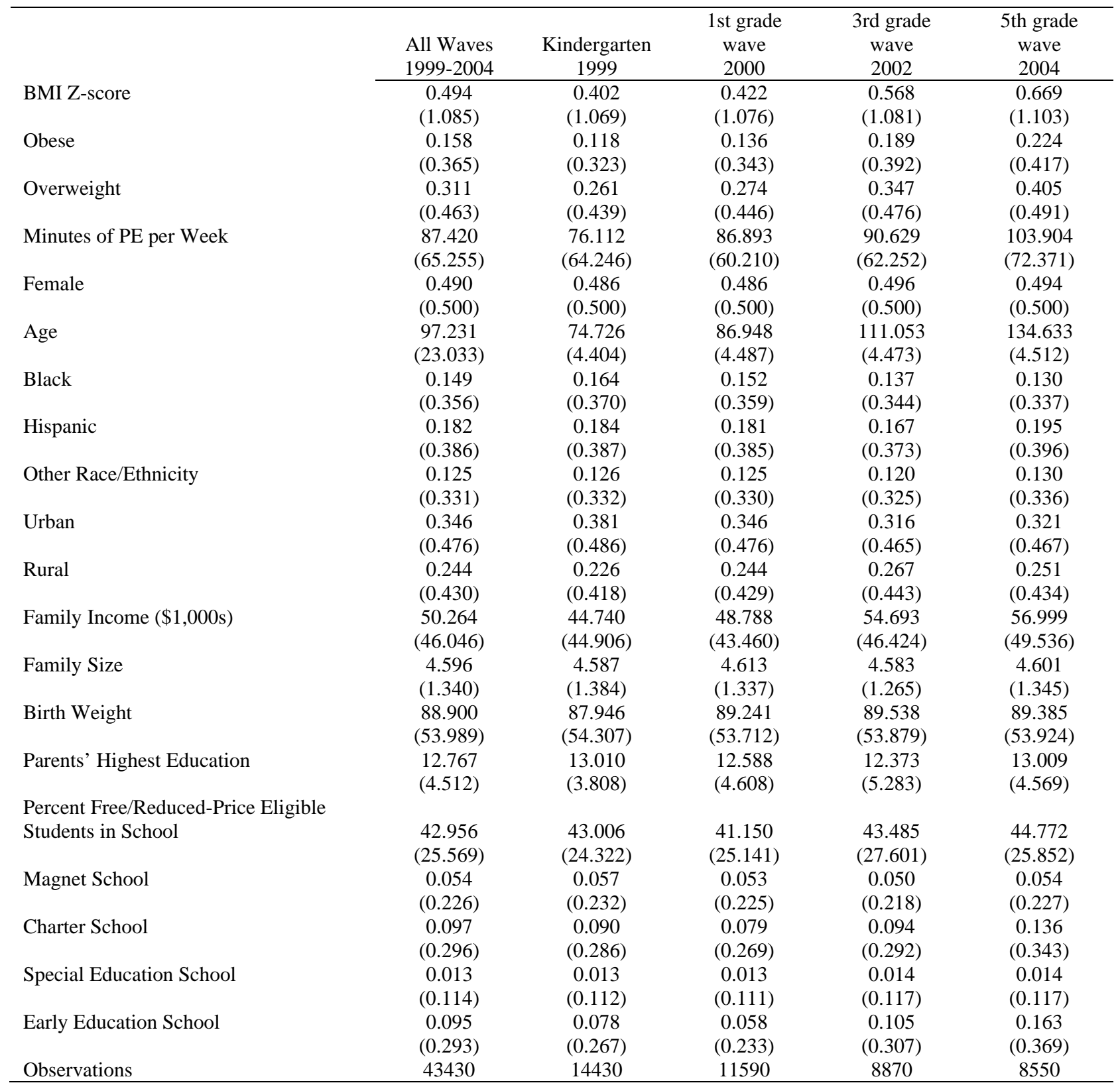

Notes: Standard deviations in parentheses. Sample sizes rounded to the nearest 10 in order to comply with Department of Education non-disclosure requirements.

Data: ECLS-K 
Table 2:

Number of States with PE Requirements by Year and Grade Level

\begin{tabular}{|c|c|c|c|c|}
\hline & $\begin{array}{c}\text { Kindergarten } \\
1999\end{array}$ & $\begin{array}{c}\text { 1st grade } \\
\text { wave } \\
2000\end{array}$ & $\begin{array}{c}\text { 3rd grade } \\
\text { wave } \\
2002\end{array}$ & $\begin{array}{c}\text { 5th grade } \\
\text { wave } \\
2004\end{array}$ \\
\hline States without a Mandate & 21 & 15 & 13 & 13 \\
\hline States with a Mandate but no Minutes Requirement & 27 & 29 & 28 & 26 \\
\hline States with a Mandate and a Minutes Requirement & 2 & 6 & 9 & 11 \\
\hline
\end{tabular}

Notes: State mandates are based on the year and the applicable grade of students in the ECLS-K data, so that the decrease in states without a mandate from 1999 to 2000 is due to state mandates that do not apply to kindergarten students. Figure 1 shows the geographic distribution of state laws in 2004. Additional details about the state laws are included in the appendix.

Sources: See Appendix. 
Table 3:

Percent of Students in the Sample Subject to a Mandate in each Year and Survey Wave

\begin{tabular}{lccccc}
\hline & All Waves & Kindergarten & $\begin{array}{c}\text { 1st grade } \\
\text { wave }\end{array}$ & $\begin{array}{c}\text { 3rd grade } \\
\text { wave }\end{array}$ & $\begin{array}{c}\text { 5th grade } \\
\text { wave }\end{array}$ \\
& $1999-2004$ & 1999 & 2000 & 2002 & 2004 \\
\cline { 2 - 6 } Students subject to a Mandate & 0.72 & 0.59 & 0.77 & 0.79 & 0.78 \\
& $(0.45)$ & $(0.49)$ & $(0.42)$ & $(0.41)$ & $(0.41)$ \\
& 43430 & 14430 & 11590 & 8870 & 8550 \\
Students subject to a Mandate with a & & & & & \\
Minutes Requirement & 0.22 & 0.06 & 0.26 & 0.27 & 0.38 \\
& $(0.41)$ & $(0.25)$ & $(0.44)$ & $(0.44)$ & $(0.48)$ \\
Average Minutes Requirement & 43430 & 14430 & 11590 & 8870 & 8550 \\
among Students subject to a Mandate & & & & & \\
with a Minutes Requirement & 117.70 & 132.02 & 118.87 & 110.70 & 117.65 \\
& $(26.75)$ & $(14.71)$ & $(22.33)$ & $(30.43)$ & $(28.45)$ \\
& 9510 & 930 & 2990 & 2380 & 3220 \\
\hline
\end{tabular}

Notes: Standard deviations in parentheses. The numbers of observations (in italics) are rounded to the nearest 10 to comply with non-disclosure requirements.

Data: Early Childhood Longitudinal Study, Kindergarten Cohort 
Table 4:

First Stage:

Relationship between State Mandates and Time in PE

\begin{tabular}{lccccc}
\hline & & Kinder- & 1st grade & 3rd grade & 5th grade \\
& All Waves & garten & wave & wave & wave \\
& $1999-2004$ & 1999 & 2000 & 2002 & 2004 \\
\cline { 2 - 6 } Number of Required Minutes & $0.1309 * *$ & 0.1256 & 0.0157 & 0.0420 & $0.3977 * * *$ \\
& $(0.0523)$ & $(0.0823)$ & $(0.0863)$ & $(0.0881)$ & $(0.0853)$ \\
F statistic & 6.267 & 2.328 & 0.0333 & 0.227 & 21.74 \\
Observations & 42910 & 14210 & 11480 & 8770 & 8470 \\
\hline
\end{tabular}

Notes: Heteroskedasticity-robust standard errors that allow for clustering within states in parentheses. The numbers of observations are rounded to the nearest 10 to comply with non-disclosure requirements. The F statistic corresponds to the hypothesis test that the coefficient for the number of required PE minutes is equal to zero. The individual and household characteristics included, but not shown, are: sex, age, grade, race/ethnicity (black, Hispanic, and other race/ethnicity, with white excluded), family income, family size, parent's education, parent's education is missing, birth weight, birth weight is missing, population density (urban or rural, with suburban excluded), and population density is missing. The school characteristics included, but not shown, are: the percent of free and reduced-price eligible students and the type of school (magnet, charter, special education, and early education, with regular excluded). The state characteristics included, but not shown, are: real per capita income, the percent of adults with a bachelor's degree, the prevalence of childhood obesity among boys and girls, the average pupil/teacher ratio in public schools, real total state tax revenue per student, real state instructional expenditures per student, and the percent of students participating in the National School Lunch Program, School Breakfast Program, and Summer Food Service Program.

Data: Early Childhood Longitudinal Study, Kindergarten Cohort 
Table 5:

Relationship between Time in PE and BMI Z-Score

\begin{tabular}{lc|c|c|c|c|c|c|c|c|c}
\hline & \multicolumn{2}{c|}{ All Waves } & \multicolumn{2}{c|}{ Kindergarten } & \multicolumn{2}{c|}{ 1st grade wave } & \multicolumn{2}{c|}{ 3rd grade wave } & \multicolumn{2}{c}{ 5th grade wave } \\
& \multicolumn{2}{c}{$1999-2004$} & \multicolumn{2}{c}{1999} & \multicolumn{2}{c}{2000} & \multicolumn{2}{c}{2002} & \multicolumn{2}{c}{2004} \\
\cline { 2 - 11 } Time in PE & $-0.0003^{* *}$ & -0.0020 & 0.0000 & -0.0106 & $-0.0005^{* * *}$ & 0.0221 & -0.0004 & -0.0132 & -0.0004 & $-0.0016^{* * *}$ \\
& $(0.0001)$ & $(0.0017)$ & $(0.0002)$ & $(0.0077)$ & $(0.0002)$ & $(0.0706)$ & $(0.0002)$ & $(0.0252)$ & $(0.0002)$ & $(0.0005)$ \\
Observations & 41720 & 41720 & 14080 & 14080 & 10810 & 10810 & 8530 & 8530 & 8310 & 8310 \\
F statistic & & 6.843 & & 2.430 & & 0.110 & & 0.229 & & 22.00 \\
Method & OLS & IV & OLS & IV & OLS & IV & OLS & IV & OLS & IV \\
\hline
\end{tabular}

Notes: Heteroskedasticity-robust standard errors that allow for clustering within states in parentheses. The numbers of observations are rounded to the nearest 10 to comply with non-disclosure requirements. The F statistic corresponds to the hypothesis test that the coefficient for the required minutes in PE is equal to zero in the first stage relationship. Additional variables included, but not shown, are: sex, age, grade, race/ethnicity (black, Hispanic, and other race/ethnicity, with white excluded), family income, family size, parent's education, parent's education is missing, birth weight, birth weight is missing, population density (urban or rural, with suburban excluded), population density is missing, the percent of free and reduced-price eligible students, the type of school (magnet, charter, special education, and early education, with regular excluded), real per capita income in the state, the percent of adults with a bachelor's degree in the state, the prevalence of childhood obesity among boys and girls in the state, the average pupil/teacher ratio in public schools in the state, real total state tax revenue per student in the state, real state instructional expenditures per student in the state, and the percent of students in the state participating in the National School Lunch Program, School Breakfast Program, and Summer Food Service Program.

Data: Early Childhood Longitudinal Study, Kindergarten Cohort 
Table 6:

Relationship between Time in PE and Additional Weight-Related Outcomes

\begin{tabular}{cccc}
\hline & OLS/Probit & IV & IV \\
& Marg. Effect & Marg. Effect & Marg. Effect (\%) \\
\cline { 2 - 4 } Obese & $-0.0001^{*}$ & $-0.0008^{* * *}$ & $-0.36^{* * *}$ \\
$(\mathrm{~F}=22.00)$ & $(0.0001)$ & $(0.0002)$ & $(0.09)$ \\
Overweight and Obese & $-0.0002^{* *}$ & $-0.0007^{* * *}$ & $-0.18^{* * *}$ \\
$(\mathrm{~F}=22.00)$ & $(0.0001)$ & $(0.0002)$ & $(0.06)$ \\
Weight Z-Score & $-0.0004^{*}$ & $-0.0014^{* * *}$ & $-0.26^{* * *}$ \\
$(\mathrm{~F}=22.07)$ & $(0.0002)$ & $(0.0005)$ & $(0.10)$ \\
\hline
\end{tabular}

Notes: The excluded instrument is the required number of minutes in PE. The sample size is 8310 for obese and overweight/obese and 8320 for weight z-score. For additional notes, see Table 5.

Data: Early Childhood Longitudinal Study, Kindergarten Cohort, $5^{\text {th }}$ grade wave (2004) 
Table 7:

Understanding the Mechanisms: Relationship between Time in PE and Physical Activity

\begin{tabular}{|c|c|c|c|}
\hline & $\begin{array}{c}\text { Non-IV } \\
\text { Marg. Effect }\end{array}$ & $\begin{array}{c}\text { IV } \\
\text { Marg. Effect }\end{array}$ & $\begin{array}{c}\text { IV } \\
\text { Marg. Effect (\%) }\end{array}$ \\
\hline Days/Wk of Vigorous Exercise & $\begin{array}{c}0.0012 * * * \\
(0.0004)\end{array}$ & $\begin{array}{c}0.0011 \\
(0.0014)\end{array}$ & $\begin{array}{c}0.03 \\
(0.04)\end{array}$ \\
\hline More Structured Activity & $\begin{array}{c}0.0001^{* *} \\
(0.0001)\end{array}$ & $\begin{array}{c}0.0008^{* *} \\
(0.0003)\end{array}$ & $\begin{array}{l}0.30^{* *} \\
(0.13)\end{array}$ \\
\hline More Physical Activity & $\begin{array}{c}0.0002^{* *} \\
(0.0001)\end{array}$ & $\begin{array}{l}0.0004 * \\
(0.0002)\end{array}$ & $\begin{array}{c}0.15 \\
(0.09)\end{array}$ \\
\hline More Aerobic Exercise & $\begin{array}{c}0.0001 \\
(0.0001)\end{array}$ & $\begin{array}{c}0.0004 \\
(0.0003)\end{array}$ & $\begin{array}{c}0.18 \\
(0.12)\end{array}$ \\
\hline Participation in Group Sports & $\begin{array}{l}-0.00001 \\
(0.0001)\end{array}$ & $\begin{array}{c}0.0002 \\
(0.0004)\end{array}$ & $\begin{array}{c}0.04 \\
(0.06)\end{array}$ \\
\hline Participation in Individual Sports & $\begin{array}{l}-0.0001 \\
(0.0001)\end{array}$ & $\begin{array}{l}-0.0004 \\
(0.0005)\end{array}$ & $\begin{array}{l}-0.09 \\
(0.11)\end{array}$ \\
\hline Participation in Rec. Sports & $\begin{array}{l}-0.0001 \\
(0.0001)\end{array}$ & $\begin{array}{c}0.0002 \\
(0.0004)\end{array}$ & $\begin{array}{c}0.03 \\
(0.07)\end{array}$ \\
\hline Participation in General Exercise & $\begin{array}{l}-0.0001 \\
(0.0001)\end{array}$ & $\begin{array}{l}-0.0005 \\
(0.0008)\end{array}$ & $\begin{array}{l}-0.12 \\
(0.21)\end{array}$ \\
\hline Participation in Dance & $\begin{array}{l}-0.0001 \\
(0.0001)\end{array}$ & $\begin{array}{l}-0.0006^{*} \\
(0.0003)\end{array}$ & $\begin{array}{l}-0.58^{*} \\
(0.30)\end{array}$ \\
\hline Participation in Karate & $\begin{array}{l}-0.00004 \\
(0.00004)\end{array}$ & $\begin{array}{l}-0.00002 \\
(0.0001)\end{array}$ & $\begin{array}{l}-0.04 \\
(0.20)\end{array}$ \\
\hline Participation in Playground Act. & $\begin{array}{l}-0.0001 \\
(0.0001)\end{array}$ & $\begin{array}{l}-0.0008 * \\
(0.0005)\end{array}$ & $\begin{array}{l}-0.13^{*} \\
(0.08)\end{array}$ \\
\hline Participation in Other Sports & $\begin{array}{l}-0.0000 \\
(0.00002)\end{array}$ & $\begin{array}{l}-0.0002 \\
(0.0002)\end{array}$ & $\begin{array}{l}-1.35^{*} \\
(0.71)\end{array}$ \\
\hline TV Minutes per Week & $\begin{array}{c}0.0218 \\
(0.0461)\end{array}$ & $\begin{array}{c}0.2132 \\
(0.1494)\end{array}$ & $\begin{array}{c}0.05 \\
(0.03)\end{array}$ \\
\hline
\end{tabular}

Notes: The sample size is 7710 and the first stage F-statistic corresponding to the IV models is 19.68 for all physical activity measures. For TV minutes the sample size is 7720 and the first stage F-statistic is 19.67. For additional notes, see Table 5.

Data: Early Childhood Longitudinal Study, Kindergarten Cohort, $5^{\text {th }}$ grade wave (2004) 
Table 8:

Falsification Tests:

Relationship between Time in PE and Implausible Weight-Related Outcomes

\begin{tabular}{lccc}
\hline & $\begin{array}{c}\text { OLS/Probit } \\
\text { Marg. Effect }\end{array}$ & $\begin{array}{c}\text { IV } \\
\text { Marg. Effect }\end{array}$ & $\begin{array}{c}\text { IV } \\
\text { Marg. Effect (\%) }\end{array}$ \\
\cline { 2 - 4 } & & & \\
Height Z-Score & -0.0001 & -0.0000 & 0.02 \\
$(\mathrm{~F}=22.07)$ & $(0.0001)$ & $(0.0005)$ & $(0.30)$ \\
Fall Kindergarten BMI Z-Score & 0.0002 & 0.0012 & 0.28 \\
$(\mathrm{~F}=18.17)$ & $(0.0001)$ & $(0.0012)$ & $(0.27)$ \\
Birth Weight (ounces) & 0.0236 & 0.0716 & 0.08 \\
$(\mathrm{~F}=21.51)$ & $(0.0155)$ & $(0.0675)$ & $(0.08)$ \\
\hline
\end{tabular}

Notes: The excluded instrument is the required number of minutes in PE. The sample size is 8320 for height zscore, 7650 for the fall kindergarten BMI Z-score, and 8470 for birth weight. For additional notes, see Table 5. Data: Early Childhood Longitudinal Study, Kindergarten Cohort, $5^{\text {th }}$ grade wave (2004) 
Table 9:

Investigating Crowd-Out:

Relationship between Time in PE and Time in Other Subjects

\begin{tabular}{lccc}
\hline \multirow{4}{*}{ Total Time } & OLS & IV & Marg. Effect (\%) \\
\cline { 2 - 4 } Recess & $1.1491^{* * *}$ & $1.6062^{* * *}$ & $0.08^{* * *}$ \\
& $(0.166)$ & $(0.575)$ & $(0.03)$ \\
Lunch & $-0.0904^{* * *}$ & -0.0780 & -0.07 \\
& $(0.023)$ & $(0.153)$ & $(0.14)$ \\
Reading & $0.0368^{* *}$ & $0.3722^{* * *}$ & $0.24^{* * *}$ \\
& $(0.014)$ & $(0.136)$ & $(0.09)$ \\
Writing & -0.0262 & $0.4416^{*}$ & $0.10^{*}$ \\
& $(0.050)$ & $(0.236)$ & $(0.06)$ \\
Math & 0.0106 & 0.0182 & 0.01 \\
& $(0.043)$ & $(0.302)$ & $(0.15)$ \\
Social Studies & $-0.1273^{* * *}$ & -0.1512 & -0.04 \\
\multirow{2}{*}{ Science } & $(0.038)$ & $(0.174)$ & $(0.05)$ \\
\multirow{2}{*}{ Music } & 0.0180 & -0.0551 & -0.03 \\
& $(0.049)$ & $(0.175)$ & $(0.10)$ \\
Art & $0.2297^{* * *}$ & 0.2977 & 0.17 \\
Foreign Language & $(0.044)$ & $(0.199)$ & $(0.12)$ \\
& 0.0384 & $-0.1779 * *$ & $-0.31^{* *}$ \\
Reference & $(0.025)$ & $(0.073)$ & $(0.13)$ \\
& 0.0157 & -0.0817 & 0.14 \\
& $(0.019)$ & $(0.071)$ & $(0.12)$ \\
& 0.0011 & -0.0146 & 0.10 \\
& $(0.014)$ & $(0.098)$ & $(0.70)$ \\
& $0.0427^{* *}$ & 0.0348 & 0.04 \\
& $(0.021)$ & $(0.077)$ & $(0.10)$ \\
\hline
\end{tabular}

Notes: In each case, the sample size is 8230 and the first stage F-statistic associated with the instrument in the first stage is 22.04. For additional notes, see Table 5.

Source: Early Childhood Longitudinal Study, Kindergarten Cohort, $5^{\text {th }}$ grade wave (2004) 
Table 10:

Investigating Spillovers:

Relationship between Time in PE and Academic Achievement

\begin{tabular}{lccc}
\hline & OLS & IV & F Statistic \\
\cline { 2 - 4 } Reading Achievement & 0.0026 & -0.0069 & 20.10 \\
Math Achievement & $(0.0038)$ & $(0.0218)$ & \\
& 0.0054 & -0.0221 & 20.13 \\
Science Achievement & $(0.0048)$ & $(0.0328)$ & \\
& $0.0066^{* *}$ & 0.0050 & 20.12 \\
\hline
\end{tabular}

Notes: The number of observations for reading achievement is 6880, and the number of observations for math and science achievement is 6890 .

Source: Early Childhood Longitudinal Study, Kindergarten Cohort, $5^{\text {th }}$ grade wave (2004) 
Table 11:

Subgroup Analyses:

Relationship between Time in Physical Education and Weight by Gender

\begin{tabular}{|c|c|c|c|c|c|c|}
\hline & $\begin{array}{c}\text { BMI Z- } \\
\text { Score }\end{array}$ & BMI Z-Score & Overweight & Overweight & Obese & Obese \\
\hline \multicolumn{7}{|l|}{ Panel A: Girls } \\
\hline Time in PE & $\begin{array}{l}-0.0005 \\
(0.0003)\end{array}$ & $\begin{array}{l}-0.0000 \\
(0.0008)\end{array}$ & $\begin{array}{c}-0.0003^{* *} \\
(0.0001)\end{array}$ & $\begin{array}{l}-0.0001 \\
(0.0004)\end{array}$ & $\begin{array}{l}-0.0001 * \\
(0.0001)\end{array}$ & $\begin{array}{l}-0.0003 \\
(0.0002)\end{array}$ \\
\hline $\begin{array}{l}\text { Observations } \\
\text { F statistic }\end{array}$ & 4110 & $\begin{array}{l}4110 \\
18.21\end{array}$ & 4110 & 4110 & 4110 & 4110 \\
\hline \multicolumn{7}{|l|}{ Panel B: Boys } \\
\hline Time in PE & $\begin{array}{c}-0.0003 \\
(0.0003)\end{array}$ & $\begin{array}{c}-0.0030 * * * \\
(0.0008)\end{array}$ & $\begin{array}{l}-0.0002 \\
(0.0001)\end{array}$ & $\begin{array}{c}-0.0012 * * * \\
(0.0003)\end{array}$ & $\begin{array}{c}-0.0001 \\
(0.0001)\end{array}$ & $\begin{array}{c}-0.0012 * * * \\
(0.0003)\end{array}$ \\
\hline $\begin{array}{l}\text { Observations } \\
\text { F statistic }\end{array}$ & 4210 & $\begin{array}{l}4210 \\
25.78\end{array}$ & 4210 & 4210 & 4210 & 4210 \\
\hline Method & OLS & IV & $\begin{array}{c}\text { Probit Marg. } \\
\text { Effect }\end{array}$ & $\begin{array}{l}\text { IV Probit } \\
\text { Marg. Effect }\end{array}$ & $\begin{array}{c}\text { Probit Marg. } \\
\text { Effect }\end{array}$ & $\begin{array}{l}\text { IV Probit } \\
\text { Marg. Effect }\end{array}$ \\
\hline
\end{tabular}

Notes: See Notes to Table 5.

Data: Early Childhood Longitudinal Study, Kindergarten Cohort, $5^{\text {th }}$ grade wave (2004) 


\section{Appendix Table:}

\section{State Physical Education Requirements for Grades K-8 in 1999 through 2007}

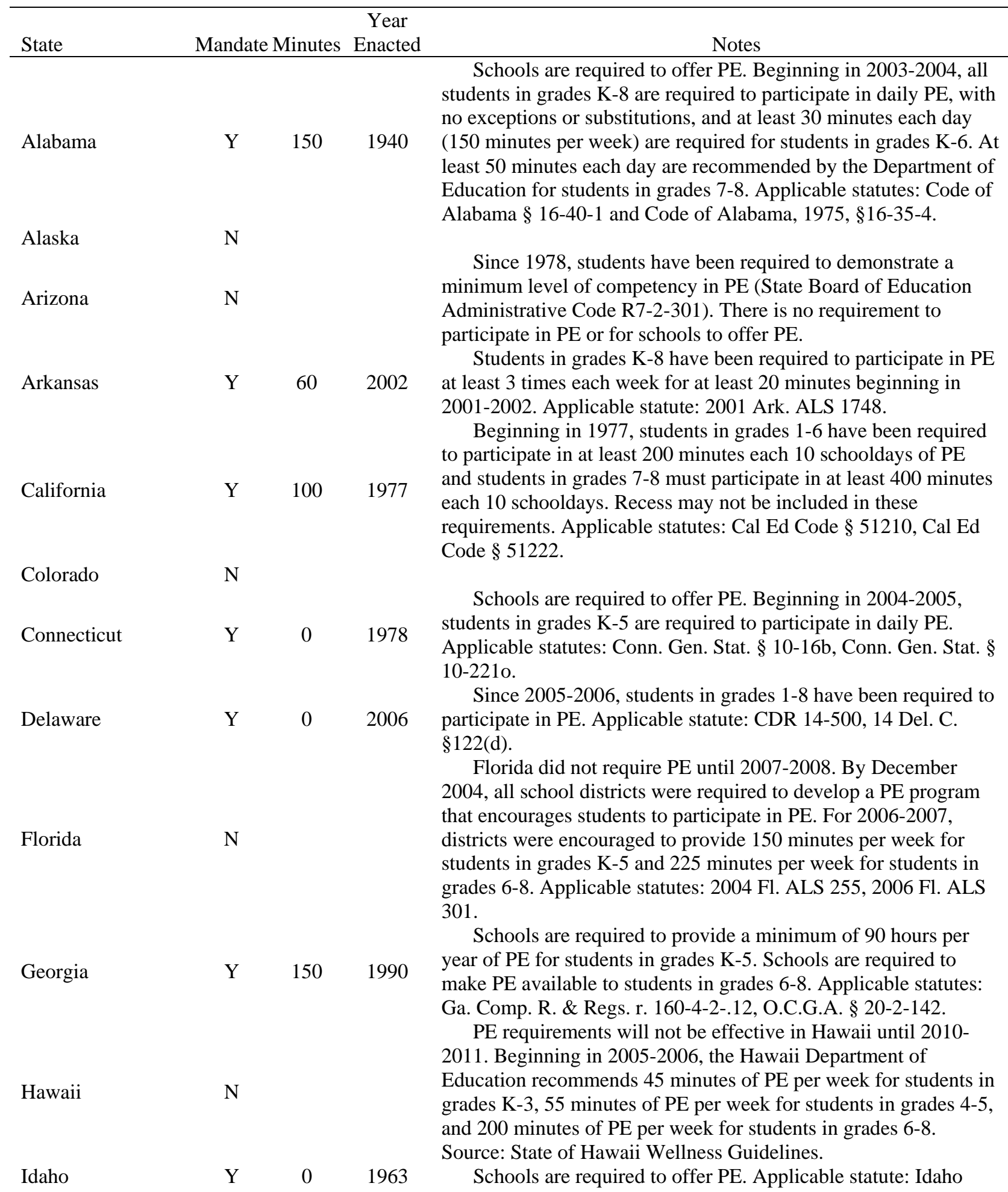


Illinois

Y

daily

1996

Indiana

$\mathrm{Y}$

0

2006

Iowa

Kansas

$\mathrm{Y}$

0

1993

Kentucky

Y

0

Louisiana

$\mathrm{Y}$

150

Maine

Maryland

Massachusetts

Michigan

Minnesota

Y

0

2006

Mississippi

$\mathrm{N}$

Missouri

Y

50

1995

Montana

Y
Code § 33-1605

Students in all grades are required to participate in daily PE. Recess may contribute to the daily PE requirement for students in all grades if recess is supervised by a certified teacher. Applicable statute: 105 ILCS 5/27-6.

Beginning in 2005-2006, schools are required to offer PE. Beginning in 2006-2007, schools are required to provide daily PE for elementary school students, which may include recess. Indiana State Board of Education recommends that students in grades 1-3 participate in 105 minutes per week of PE, students in grades 4-6 participate in 75 minutes per week, and students in grades 6-8, when grade 6 is included in a middle school, participate in 100 minutes per week. Applicable statutes: Burns Ind. Code Ann. § 20-30-5-7, Burns Ind. Code Ann. § 20-30-5-7.5, 511 IAC 6.1-52.5

Physical education is required to be taught in grades 1-8. Applicable statute: Iowa Code § 256.11.

Schools are required to offer PE in elementary and secondary school to receive accreditation. Beginning in 2005-2006, the state Board of Education recommends at least 100 minutes per week. The available state statutes date back only to 2005. According to the Shape of the Nation and Trust for America's Health reports, the requirement dates back to at least 1993. Applicable statute: K.A.R. § 91-31-32

Beginning in 2006-2007, students in grades K-8 are required to participate in PE as part of the state curriculum. Applicable statute: 704 KAR 3:303.

Schools are required to provide PE for at least 30 minutes each day to students in grades 1-6. Applicable statute: 2004 La. ALS 734, La. R.S. 17:17.1, State Bulletins 102 and 103.

Schools are required to offer PE. Applicable statute: $2001 \mathrm{Me.}$ ALS 454.

Schools are required to offer PE. Applicable statute: Md. EDUCATION Code Ann. § 7-409.

Schools are required to offer PE. Applicable statute: ALM GL ch. $71, \S 1$.

Schools are required to offer PE. Beginning in 2003-2004, the state Board of Education recommends that all schools offer PE for 150 minutes per week for grades K-5 and for 225 minutes per week for grades 6-8. Applicable statute: MCLS § 380.1502.

Students are required to participate in PE beginning in 20052006 in grades 1-10. Applicable statutes: 2005 Minn. ALS 5, Statute 120A-22

Students in grades K-8 are required to participate in PE for 150 minutes per week beginning in 2007-2008. Between 20022003 and 2006-2007, the legislature recommends that students in grades K-8 participate in PE for 150 minutes per week. Applicable statutes: Miss. Code Ann. § 37-13-134, 2002 Miss. ALS 585.

Schools are required to provide PE to all students in all public schools at least as far back as 1995. Beginning in 2001-2002, students in grades K-5 are required to participate in 50 minutes per week of PE and students in grades 6-8 are required to receive 3000 hours of instruction in PE per year. Applicable statutes: $\S$ 161.102 R.S.Mo. and Missouri School Improvement Program.

Schools are required to offer PE. Applicable statute: MONT. ADMIN. R. 10.54.2501. 
Nebraska

Y

0

Nevada

$\mathrm{N}$

New Hampshire

Y

0

1975

New Jersey

Y

150

1967

New Mexico

Y

0

New York

Y

120

1983

North Carolina

Y

0

North Dakota

$\mathrm{Y}$

90

2001

Ohio

Oklahoma

$\mathrm{N}$

Oregon

Pennsylvania

Rhode Island

South Carolina
Y

100

1956

Y $\quad 0$

1993

1998

1999

1976
Schools are required to offer PE in elementary and middle schools. The initial date of this requirement is unknown. Applicable statute: Nebraska Admin. Code Title 92, Ch. 10004.03A9.

There is no mandate that students participate in PE, but, beginning in 1999-2000, PE “must be taught as applicable for grade levels and to the extent practicable in all public schools." Applicable statute: Nev. Rev. Stat. Ann. § 389.018.

$\mathrm{PE}$ is required to be taught to students in all grades beginning in 1975 or possibly earlier. Beginning in 2004-2005, the school boards of each school district were required to adopt a policy recommending daily PE. Applicable statute: RSA 189:10, RSA 189:11-a.

Students are required to take courses in PE and health in grades 1-12 for a combination of 150 minutes per week. Local school districts determine the percentage of the 150 minutes that is allocated to PE. Applicable statute: N.J. Stat. § 18A:35-7, N.J. Stat. § 18A:35-8.

Schools are required to provide PE in grades 1-8. Applicable statute: N.M. Stat. Ann. § 22-13-1.

Beginning in 1982-1983, students in grades K-3 must participate in PE daily and students in grades 4-6 must participate in $\mathrm{PE}$ at least 3 times per week. Students in grades K-6 must participate in at least 120 minutes per week. Schools are required to offer PE to students in grades 7-8 at least 3 times per week in one semester and 2 times per week in the other semester. Applicable statute: 8 NYCRR § 135.4.

Students in grades K-8 are required to participate in PE. The recommended minimum amount of $\mathrm{PE}$ is 150 minutes per week for students in grades K-5 and 225 minutes per week for students in grades 6-8. The initial date of this requirement is unknown. Applicable statutes: Policy ID Number: GCS-S-000, N.C. Gen. Stat. § 115C-12.

Students in grades K-8 are required to participate in PE. PE is required for students in grades $7-8$ for 80 minutes per week and for 90 minutes per week for students in grades 1-6. Applicable statutes: N.D. Cent. Code, § 15.1-21-01, Administrative Rules 6719-01-34 and 67-19-01-35.

Schools are required to offer PE for students in all grades. Applicable statute: OAC Ann. 3301-35-04.

Beginning in 2006-2007, schools are required to provide PE for elementary school students for at least 60 minutes per week. This requirement does not apply to middle school students and PE was not mandated prior to 2006-2007. Applicable statute: 70 Okl. St. $§ 11-103.9$.

Beginning in 1997-1998, schools are required to offer PE to students in all grades. Applicable statute: Or. Admin. R. 581-0221210.

$\mathrm{PE}$ is required to be taught to students in all grades. Applicable statute: 22 Pa. Code § 4.27.

Students are required to participate in PE for at least 20 minutes each day in grades 1-12. Recess cannot count towards the PE requirements. Applicable statute: Rules and Regulations of School Health Programs.

Students are required to participate in PE. Beginning in 20062007, students in K-5 must participate in physical activity for at 


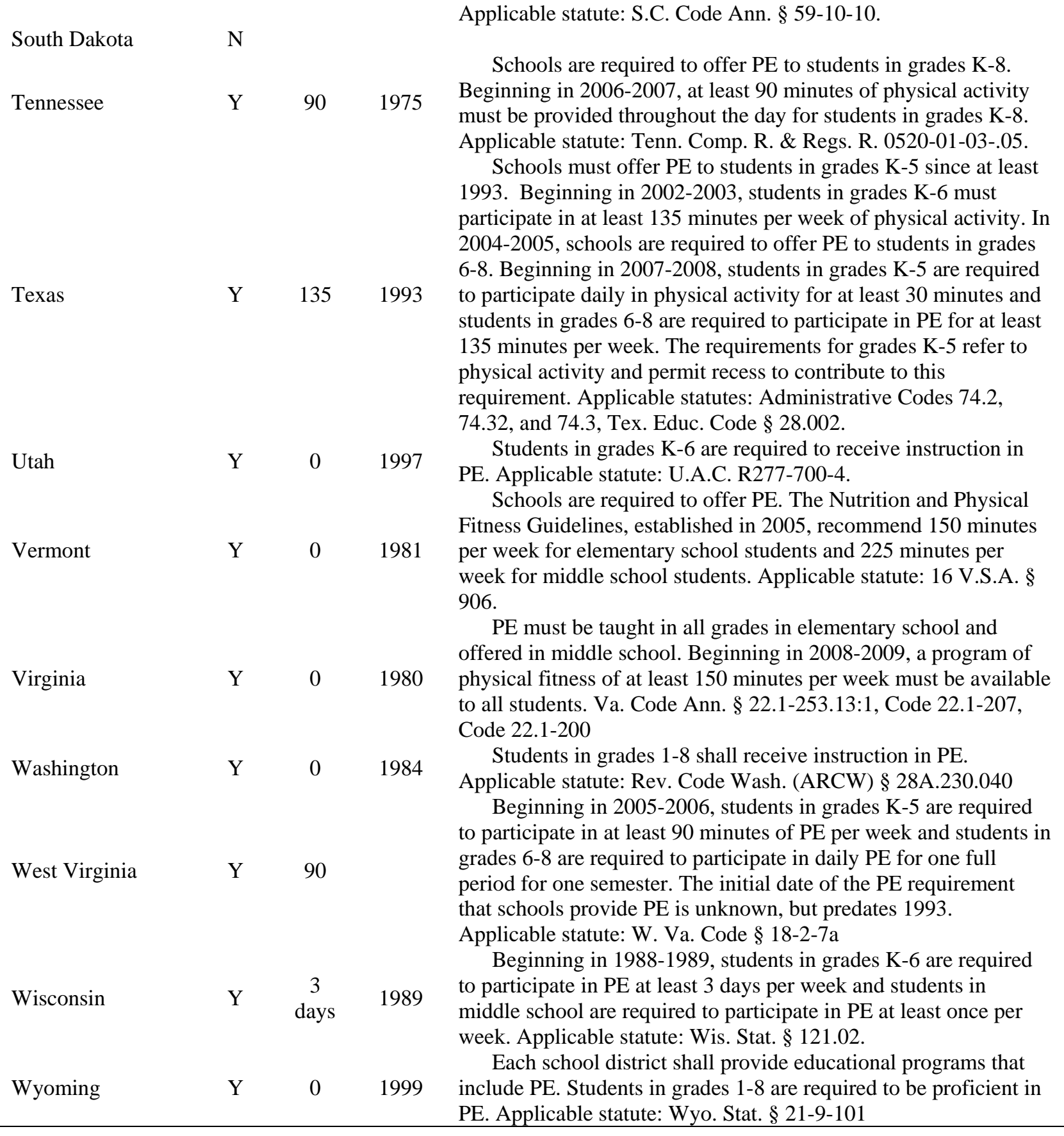

least 150 minutes per week of which 60 minutes must be PE. Applicable statute: S.C. Code Ann. § 59-10-10.

Schools are required to offer PE to students in grades K-8. Beginning in 2006-2007, at least 90 minutes of physical activity .

plicable statute: Tenn. Comp. R. \& Regs. R. 0520-01-03-.05. Schools must offer PE to students in grades K-5 since at least 1993. Beginning in 2002-2003, students in grades K-6 must participate in at least 135 minutes per week of physical activity. In 2004-2005, schools are required to offer PE to students in grades students in grades 6-8 are required to participate in PE for at least 135 minutes per week. The requirements for grades K-5 refer to requirement. Applicable statutes: Administrative Codes 74.2, .32, and 74.3, Tex. Educ. Code $\S 28.002$.

Applicable statute: U.A.C. R277-700-4. Schools are required to offer PE. The Nutrition and Physical Fitness Guidelines, established in 2005, recommend 150 minutes per week for elementary school students and 225 minutes per week for middle school students. Applicable statute: 16 V.S.A. § offered in middle school. Beginning in 2008-2009, a program of physical fitness of at least 150 minutes per week must be available to all students. Va. Code Ann. § 22.1-253.13:1, Code 22.1-207, ode 22.1-200

Aplicable statute: Rev. Code Wash. (ARCW) § 28A.230.040 Beginning in 2005-2006, students in grades K-5 are required to participate in at least 90 minutes of PE per week and students in period for one semester. The initial date of the PE requirement that schools provide PE is unknown, but predates 1993.

Applicable statute: W. Va. Code § 18-2-7a middle school are required to participate in PE at least once per ek. Applicable statute: Wis. Stat. § 121.02 PE. Applicable statute: Wyo. Stat. § 21-9-101

Sources: State statues as found in LexisNexis and are cross-referenced with curriculum requirements published by states' Departments of Education, the National Association of State Boards of Education State School Health Policy Database, the 1993, 2001, and 2006 Shape of the Nation Reports, and the TFAH annual reports that began in 2004. The appropriate state statues and amendments are listed in the notes column, if available. The year enacted is the earliest year with PE requirements known according to these sources. The reported PE requirements are applicable to students in public schools. The minutes column documents the required minutes of PE per week. 